\title{
Health Coaching in Severe COPD After a Hospitalization: A Qualitative Analysis of a Large Randomized Study
}

\author{
Roberto P Benzo MD MSc, Janae L Kirsch, Julie C Hathaway MSc, Charlene E McEvoy MD, \\ and Kristin S Vickers PhD
}

\begin{abstract}
BACKGROUND: We recently demonstrated in a randomized study the feasibility and effectiveness of telephone-based health coaching using motivational interviewing on decreasing hospital readmissions and improving quality of life at 6 and 12 months after hospital discharge. In this qualitative study, we sought to explore the health-coaching intervention as seen from the perspective of the participants who received the intervention and the coaches who delivered it. METHODS: Semistructured participant interviews $(n=24)$ and a focus group of all health coaches $(n=3)$ who participated in this study were conducted. Interviews and focus group were recorded and transcribed verbatim. Transcripts were analyzed using coding and categorizing techniques and thematic analysis. Mixed-method triangulation was used to merge quantitative and qualitative data. RESULTS: Content analysis revealed 4 predominant themes of the coaching intervention: healthcoaching relationship, higher participant confidence and reassurance (most related to improvement in physical quality of life), improved health-care system access (most related to decreased hospital readmissions), and increased awareness of COPD symptoms (most related to improvement in emotional quality of life). The strongest theme was the relationship with the health coach, including coach style and motivational interviewing approach. Health coaches' focus group also noted the importance of the coaching relationship as the most significant theme. CONCLUSIONS: This study provided themes to further inform the delivery and implementation of health-coaching interventions in patients with COPD after hospital discharge. Health coaching forged partnerships and created a platform for patient engagement, which was confirmed by both participants and health coaches. Key words: COPD; self-management; health coaching; quality of life; motivational interviewing. [Respir Care 2017;62(11):1403-1411. (C) 2017 Daedalus Enterprises]
\end{abstract}

\section{Introduction}

We recently demonstrated in a randomized study $(N=215)$ the feasibility and effectiveness of telephonebased health coaching using motivational interviewing on decreasing hospital readmissions and improving quality of life at 6 and 12 months after hospital discharge. Motiva-

\footnotetext{
Dr Benzo and Ms Kirsch are affiliated with the Mindful Breathing Laboratory, Division of Pulmonary and Critical Care Medicine, Mayo Clinic, Rochester, Minnesota. Ms Hathaway is affiliated with the Section of Patient Education, Mayo Clinic, Rochester, Minnesota. Dr McEvoy is affiliated with the HealthPartners Institute for Education and Research, Bloomington, Minnesota. Dr Vickers is affiliated with the Division of Psychiatry and Psychology, Mayo Clinic, Rochester, Minnesota.
}

Dr. Benzo is supported by NHLBI, National Institutes of Health, Grant R01HL094680. The authors have disclosed no conflicts of interest. tional interviewing and health coaching have individually demonstrated improved behavior change and self-management $^{1-4}$ for patients with chronic conditions ${ }^{5,6}$ and vulnerable people, such as previously hospitalized patients with COPD. ${ }^{6,7}$ In combination, motivational interviewing-based health coaching significantly improved self-managing abilities ${ }^{8}$ self-efficacy, ${ }^{9}$ health status, ${ }^{10,11}$ and medication ad-

\footnotetext{
Supplementary material related to this paper is available at http:// www.rcjournal.com.

Correspondence: Roberto Benzo MD MSc, Mindful Breathing Laboratory, Division of Pulmonary and Critical Care, Mayo Clinic, 200 First Street SW Gonda 18-440, Rochester, MN 55902. E-mail: benzo.roberto@mayo.edu.
}

DOI: $10.4187 /$ respcare. 05574 
herence ${ }^{10}$ in participants, with varying effects on quality of life, ${ }^{8,10}$ all contributing factors to hospitalization.

Multiple factors contribute to COPD hospitalizations, many of which are not COPD-specific, like comorbidities and psychosocial issues ${ }^{12-16}$; however, reducing rehospitalization continues to be a major area of focus in health care. Living with COPD has many challenges, since as symptom severity progresses, the ability to visit family, attend medical appointments, and perform enjoyable activities becomes increasingly more difficult, a contributing factor to depressive symptoms ${ }^{17}$ and decreased quality of life, ${ }^{18}$ which are strongly associated with poorer outcomes, such as hospitalizations. ${ }^{19-24}$

This qualitative report aims to further explore our results of the recently published randomized study in which we found that motivational interviewing-based telephone health coaching reduced rehospitalizations and increased quality of life in subjects with COPD when applied after hospital discharge. ${ }^{25,26}$ In this study, we specifically explored participants' and health coaches' perceptions of the intervention through qualitative interviews and focus groups. Our results may inform the implementation efforts for post-hospitalization health coaching in COPD and may inform the coaching conversations related to the specific needs of the participants.

\section{Methods}

We conducted semistructured interviews of participants who completed ${ }^{25}$ the majority of the intervention. Full details of the original study can be found in a recently published article. ${ }^{26}$ At the time of this study, of the 108 participants randomized to the intervention, 26 were deceased, 6 were still participating in the health-coaching intervention, 9 were unreachable to be invited by telephone or letter, and 12 had not completed this study's cut-point definition for intervention completion (set arbitrarily at $80 \%$ ). The interview guide explored the participants' broad view of the study as well as specific openended questions about the health coaching, telephone call logistics, self-management, and aspects they disliked about the intervention (see Appendix 1 in the supplementary materials at http://www.rcjournal.com). The semistructured interview followed guidelines for minimizing bias and increasing the reliability and validity of interview data. ${ }^{27} \mathrm{In}$ addition, rating scales assessed call frequency, perceived helpfulness of the study, and participant confidence in managing health $(0=$ not at all helpful, no confidence; $10=$ very helpful, extremely confident). Participants were interviewed by JLK and JH, individuals who are familiar with qualitative methods and the logistics of the original study intervention but did not have any knowledge of the individual participants or their outcomes.

\section{QUICK LOOK}

\section{Current knowledge}

Health coaching is becoming a prevalent method for effective communication and behavioral change (selfmanagement) in chronic respiratory disease management, particularly in COPD. Recent randomized studies support health coaching as a feasible and effective way to decrease hospital readmissions, as well as sustainably improve quality of life. However, the mechanism behind how it works is not currently understood.

\section{What this paper contributes to our knowledge}

Our study demonstrates that health coaching was effective from a qualitative standpoint. Participants with COPD and providers who received or delivered the health-coaching intervention may help to inform future health-coaching interventions in COPD patients. Health coaching forged partnerships and created a platform for engagement. Both participants and health coaches noted the importance of this relationship.

To further understand the health-coaching intervention and its outcomes, the health coaches $(n=3$, one respiratory therapist at one institution and 2 nurses at the second institution) who were part of the original intervention ${ }^{28}$ participated in a focus group. Each health coach had $\geq 2 \mathrm{y}$ of experience in the intervention. Focus group questions were developed by the study team and were primarily aimed at assessing the health coaches' perceptions of the intervention's strengths and weaknesses as well as the health coaches' personal experience delivering the intervention (see supplementary Appendix 2).

Participant interviews and the health coaches' focus group were audio recorded and transcribed verbatim. Each transcribed interview was independently open-coded ${ }^{29}$ by 2 study team members. The coders then reviewed and discussed their coding ${ }^{29}$ and the discrepancies that occurred. Differences were discussed, agreement achieved, findings converged, and selective coding performed; changes were noted in the codebook. Modifications to the interview guide were made as necessary throughout the process. ${ }^{30}$ Investigators with extensive experience in qualitative methods analyzed the transcripts, using coding and categorizing techniques and thematic analysis. ${ }^{31}$

The health coach focus group transcripts were similarly analyzed with methods of content analysis. Coders were also blinded to the individual participant outcomes.

Data triangulation through the combination of qualitative and quantitative results was employed to further explore the data. For the triangulation analysis, participants were classified as improving quality of life assessed by the 


\section{Health Coaching in Severe COPD}

Chronic Respiratory Questionnaire. We specifically used the emotional summary score (composed by the emotional and mastery domains) and the physical summary score (composed by the dyspnea and fatigue domains), as we reported in the original publication and defined improvement or not, ${ }^{32}$ if they met the minimally clinically important difference of 0.5 points (in a 1-7 scale), ${ }^{33}$ between baseline and 6-month measures and if they reduced hospitalizations during the study period compared with the year before the study. We defined reducing hospitalizations as a participant having a decrease in hospitalizations of $\geq 1$ during the 12 months after randomization compared with the year before the study. ${ }^{26}$ Binary variables (improved or not) were created and then associated with participant qualitative themes. The latter aimed to explore the relationship between quantitative improvement and the participant's perception of the intervention. Participants completed the Working Alliance Inventory ${ }^{26}$ at the end of the intervention during the original study. This validated tool, which has a total score and 3 therapeutic subdomains of task, bond, and goal, was used to assess the therapeutic relationship.

Study procedures were approved by the institutional review board (approval 15-002368). No remuneration was provided for participants of this study.

\section{Results}

\section{Participant Interviews}

Of the 55 eligible participants, 24 consented and completed interviews. Interviews were stopped when data saturation was reached, and no new perspectives or themes emerged. The participants' demographic and baseline history data (collected in the clinical trial) were compared with those in the larger intervention cohort (Table 1). The interviewed sample proved representative, with the only meaningful difference being in continual supplemental oxygen use with activity or sleep.

Most participants viewed the intervention as very helpful, were highly confident in their ability to manage their health, and would recommend health coaching to other patients with COPD (Table 2). Table 2 shows some variability in opinion about the frequency of health-coaching calls, with more wanting additional calls toward the study's end.

Results of content analysis pooled across independent coders revealed 4 predominant themes: health-coaching relationship, participant awareness, participant confidence and reassurance, and health-care system access (Table 3). The strongest theme was the importance of the coaching relationship, including coaching style and approach. Explicit and implicit content provided evidence of the perceived personal benefit of the coaching relationship. Data consistently revealed that there were specific qualities of the coach that facilitated the coaching relationship. Coaches were viewed as friendly and likable ("a really good person"; "very nice and helpful"), positive (eg, "she could always bring my spirits up"; "very encouraging"), informed (eg, "knew good information to give me at the right time"), and available ("if she didn't answer she would call me back soon").

The interview guide intentionally included questions to elicit potential negative feedback and missed opportunities associated with the intervention and its delivery, to facilitate negative case analysis. However, interview questions and probes did not reveal areas of concern and instead revealed only some individual preferences for program delivery and timing. Table 4 provides representative quotes illustrating the additional themes of perceived reassurance from coach/coaching, more self-awareness of COPD symptoms and self-management, and perceived improvement in timely access to health care. The Working Alliance Inventory $^{26}$ results showed that participants scored $87 \%$ of the maximum score in all 3 therapeutic subdomains of task, bond, and goal in indicating the effectiveness of the healthcoaching intervention on participant engagement.

\section{Triangulation of the Qualitative and Quantitative Data}

The qualitative theme of participant awareness appeared to be an important theme related to improvement in the emotional quality of life at 6 months after hospital discharge (Fig. 1A). Participant confidence and reassurance was the predominant theme associated with improvement in physical quality of life at 6 months after discharge (Fig. 1B). Facilitated access to the health-care system (through the health coach) was the predominant theme associated with reduced hospitalizations (Fig. 1C). All participants, regardless of improvement in the physical and emotional quality of life or hospitalization rates, rated the health coaching relationship as a highly important theme (Fig. 1). We did not formally test these comparisons due to data limitations in this post hoc mixed-method analysis, yet we did observe the potential relationship between important components of health coaching and quality of life.

\section{Health Coach Focus Group}

All 3 study health coaches who delivered the intervention in the randomized study ${ }^{34}$ participated in the focus group. The conversation was rich, with a detailed discussion of the intervention, with emphasis on the initial challenges of learning motivational interviewing-based health coaching. The health coaches perceived the positive value of the intervention not only for the participant but also for themselves. 
Table 1. Baseline Clinical and Demographic Characteristics

\begin{tabular}{|c|c|c|c|}
\hline Characteristics & $\begin{array}{c}\text { Original Study No } \\
\text { Interview Cohort }(n=84)\end{array}$ & $\begin{array}{l}\text { Qualitative Study } \\
\text { Cohort }(n=24)\end{array}$ & $P$ \\
\hline Age, mean $\pm \mathrm{SD}$ y & $68.4 \pm 10.0$ & $69.5 \pm 9.24$ & .32 \\
\hline Site, $n(\%)$ & & & .24 \\
\hline Health Partners & $43(51.2)$ & $9(38)$ & \\
\hline Mayo Clinic & $41(48.8)$ & $15(62)$ & \\
\hline Education, $n(\%)$ & & & .51 \\
\hline Post-secondary education & $37(44)$ & $15(62)$ & \\
\hline Marital status, $n(\%)$ & & & .22 \\
\hline Married & $37(44)$ & $17(71)$ & \\
\hline Male sex, $n(\%)$ & $35(42)$ & $11(45)$ & .72 \\
\hline Continuous supplemental oxygen, $n(\%)$ & $35(45.5)$ & $5(21)$ & .031 \\
\hline Supplemental oxygen with activity or sleep, $n(\%)$ & $42(54.5)$ & $12(50)$ & .70 \\
\hline Participant-reported exacerbation, $n(\%)$ & & & .94 \\
\hline Within the last 12 months & $63(86.3)$ & $20(87)$ & \\
\hline$\geq 2$ exacerbations in past 12 months & $40(48)$ & $12(50)$ & \\
\hline Previous health-care utilization, $\%$ & & & .73 \\
\hline Hospitalization, past 12 months & 58 & 54 & \\
\hline Charlson comorbidity index, mean $\pm \mathrm{SD}$ & $3.798 \pm 1.789$ & $3.25 \pm 1.59$ & .18 \\
\hline $\mathrm{FEV}_{1}$, mean $\pm \mathrm{SD} \%$ predicted & $41.1 \pm 17.4$ & $37.9 \pm 16.3$ & .63 \\
\hline mMRC, $n(\%)$ & & & .40 \\
\hline 0 & $2(2.9)$ & $0(0)$ & \\
\hline 1 & $9(12.9)$ & $2(9)$ & \\
\hline 2 & $11(15.7)$ & $1(4)$ & \\
\hline 3 & $43(61.4)$ & $20(87)$ & \\
\hline 4 & $5(7.1)$ & $0(0)$ & \\
\hline \multicolumn{4}{|l|}{ Quality of life CRQ, mean \pm SD } \\
\hline Physical function (dyspnea and fatigue) & $4.045 \pm 1.055$ & $4.1 \pm 1.1$ & .91 \\
\hline Emotional function (mastery and emotion) & $4.6 \pm 1.3$ & $4.5 \pm 1.2$ & .73 \\
\hline \multicolumn{4}{|l|}{ Daily activity, mean $\pm \mathrm{SD}$} \\
\hline Steps & $2,383.4 \pm 2,141.0$ & $2,625.8 \pm 1,719.9$ & .27 \\
\hline Physical activity level & $1.3 \pm 0.2$ & $1.3 \pm 0.2$ & .84 \\
\hline Sedentary $(<2$ METS $)$, mean \pm SD min & $1,241.7 \pm 127.5$ & $1,234.5 \pm 120.5$ & .78 \\
\hline Light activity (2-4 METS), mean \pm SD min & $133.2 \pm 116.9$ & $133.7 \pm 113.8$ & .86 \\
\hline Moderate activity (4-6 METS), mean \pm SD min & $8.009 \pm 12.4$ & $7.9 \pm 13.4$ & .49 \\
\hline Vigorous activity ( $>6$ METS), mean \pm SD min & $0.267 \pm 0.9$ & $0.3 \pm 1.0$ & .65 \\
\hline Resting metabolic rate, mean $\pm \mathrm{SD} \mathrm{cal} / 24 \mathrm{~h}$ & $1,517.1 \pm 318.7$ & $1,564.8 \pm 286.7$ & .35 \\
\hline Total energy expenditure, mean $\pm \mathrm{SD} \mathrm{cal} / 24 \mathrm{~h}$ & $2,001.9 \pm 471.7$ & $2,057.3 \pm 357.1$ & .28 \\
\hline \multicolumn{4}{|l|}{$\begin{array}{l}\mathrm{mMRC}=\text { modified Medical Research Council dyspnea scale } \\
\mathrm{CRQ}=\text { Chronic Respiratory Questionnaire } \\
\text { METS = metabolic equivalent }\end{array}$} \\
\hline
\end{tabular}

Relationship With Participants Over Time Was Highly Valued. Health coaches appreciated the opportunity to have time for ongoing communication and to feel like a source of support and positivity:

It was incredibly rewarding as a nurse to have the luxurious opportunity to focus on one person in a caring relationship. I had never had that before.

I got the sense I was a positive person to talk to. Health-care interactions were not usually positive or optimistic for these people. It felt good when they were willing to stick with me for a long time.
They liked the fact that someone was checking in with them and cared enough to give them a call, even though it was part of the study. It was always a friendly conversation. There was something fun about making the call.

Health-Coaching Skills and Confidence Improved Over Time. Each coach described a learning curve in moving from traditional education/nursing/clinical care to a healthcoaching role. Motivational interviewing strategies and education within a self-management framework were initially challenging. The 3 health coaches rated their 
Table 2. Categorical Responses

\begin{tabular}{lc}
\hline \hline \multicolumn{1}{c}{ Parameters } & Values \\
\hline Confidence in taking care of health, mean \pm SD & $8.05 \pm 1.99 *$ \\
Helpfulness of the intervention, mean \pm SD & $9.60 \pm 0.60 *$ \\
Frequency of calls, $\dagger \%$ & 22 \\
$\quad$ Too little & 78 \\
About right & 0 \\
Too much & \\
Frequency of calls at end of study, $\dagger \%$ & 43 \\
Too little & 57 \\
About right & 0 \\
Too much & 96 \\
Recommendation, $\%$ & \\
$\quad$ Yes & \\
& * Rated on a scale from 0 to $10(0=$ not at all confident/helpful; $10=$ very confident/helpful). \\
$\dagger$ “In regard to the frequency of the phone calls, was it too much, too little, or about right?" \\
\hline
\end{tabular}

Table 3. Key Themes of Health Coaching in COPD Subjects

\begin{tabular}{l}
\hline Health-care system access \\
Contact person \\
Ease of getting answers \\
Emergency medication \\
Participant awareness \\
Knowledge of symptoms \\
Attention to symptom progression \\
Impact of emotions and exercise \\
Participant confidence and reassurance \\
"Someone keeping track of me" \\
Security blanket \\
Learning to relax in panic \\
Relationship With the Coach \\
Supportive, positive, friendly \\
Sharing of ideas \\
Assistance with questions or issues \\
Provided information to make decisions
\end{tabular}

confidence to deliver the intervention (scale from $0-10$; $10=$ most confident), as low initially (ratings of 4,4 , and 3 ) and high at the end (all rated an 8). Their advice to clinicians learning to be a health coach: "Practice, practice, practice" and "Stick with it!"

The Collaborative and Motivational Nature of Coaching Helped to Avoid Resistance and Conflict. Coaches worked with participants to select personally relevant selfmanagement targets, and areas of low motivation and frustration (eg, smoking cessation) could be deferred. The flexibility of this approach improved participant engagement, according to health coaches:

I see motivational interviewing as a way to be with people ... I found it very valuable in this project ... It was more about what was more important to them at that time and not be something that we are preaching at them.

Making it OK to work on what was important or a priority for them at the time because all of the patients who I worked with knew, "I have this to do and that to do and another thing to do." Moreover, to be able, just [to] step back and say, "For right now, I am just going to work on breathing." That was always my hunch of something that got a hook of engagement and got people kind of "on board" with the program, and in particular, over time.

Health coaches identified some challenges in the delivery of the intervention and opportunities for future healthcoaching training: Health coaches were concerned about their participants with depression or other emotional distress, perceiving them as less engaged and less likely to make progress with self-management goals. Further, health coaches agreed that most participants were highly unlikely to want to address mood management strategies, although included as part of self-management. Health coaches felt less competent and effective with significantly emotionally frail (high fear, anxiety, or depressive symptomatology) participants. A minor concern was the challenge of coaching over the telephone, leading them to recommend an initial face-to-face visit before telephone when possible. Also, follow-up calls after many months sometimes lacked engagement and enthusiasm, but when an exacerbation or illness occurred, re-engagement and motivation were high.

\section{Discussion}

Participants viewed health coaching as an effective intervention in COPD following hospital discharge, which impacted many aspects of the individual's life in addition to COPD. Engagement between the coach and the participant seems to be a key ingredient for perceived success. Whereas the original intervention included an exercise component and the use of antibiotics and prednisone for exacerbations, our randomized study ${ }^{26}$ showed that the health coach was the most significant factor associated with the effectiveness of the intervention. The current study found that the connection with a knowledgeable and personable individual in the health-care setting helped to encourage self-managing abilities, provide reassurance, and increase perceived awareness through working on goals that were meaningful to the participant. Patient engagement, particularly in the COPD population, is critical to promote positive behavior change and can have significant effects on health-care utilization and quality of life. ${ }^{35,36}$ Embracing the participants' values seemed to assist in the health coach-participant relationship and was perceived by 


\section{Health Coaching in Severe COPD}

Table 4. Participant Interview Results: Predominant Themes and Representative Quotes

Health coaching relationship

P05: [The coach] was very positive. She was very encouraging. I had a good time plus I had to work!

P11: I like that I had a place to get some information, to bounce off things that were happening.

P15: It was very enlightening and kind of informative and yet relaxing knowing that someone on the other end of the line was trying to solve my problems.

P10: [The coach] was always helping in the fact that she brought my spirits up. No matter what I was thinking.

Participant awareness

P18: If I did start to have an exacerbation, I watched for signs and symptoms a lot more closely.

P17: I suppose it (emergency plan) raises my awareness to some extent. I'm on medications and nebulizer and stuff so it's something that I'm very aware of all the time.

P04: It made me more aware of how exercise does make you feel better, if you do it. And we also discussed diet. So I'm a little more aware of what I'm eating and when.

P02: I just took it (emergency plan medication) a few weeks ago but I waited a few days, you know. But I could tell by my breathing. I can almost tell, when I get so short of breath, it's time to start it. If I would wait then that's when I get into trouble and get hospitalized.

Health-care system access

P07: If I had a problem, she would talk to the pulmonologist and then call me back, that type of thing.

P16: I think that is probably the most valuable thing about that study is having a contact person that you can go to. I've done some studies where you didn't know who in the devil you were supposed to call.

P08: I liked it because she helped me and when she couldn't help me, she steered me on to who could help me.

P01: We said, "This is really nice. We have someone that we can call in case I get sick."

P16: If I ever had a question, I always had (my coach) to go to. When I felt like I needed to take my emergency dose of Prednisone I felt like I had an easy connection to getting some care. Nice having that connection with an actual person. I was able to get to her rather than to get to a pulmonologist.

Participant confidence and reassurance

P13: It gives you the confidence to trust your instincts, and to know, "OK, something is not right, I need to trust myself. I can do this."

P07: I felt like somebody was keeping track of me.

P01: I'm on oxygen 24/7 ... so, I'm more leery nowadays. But it made me feel secure knowing that I had that medicine and her phone number and if I got really sick, I could call and get some treatment. There was that security blanket.

the health coaches and participants to ignite genuine motivation for behavioral change rather than adding items to the participants' list of things they should do to manage their health. In particular, the relationship with the coach through motivational interviewing-based health coaching provides a unique avenue to train health coaches using a solid theoretical framework. ${ }^{37}$ That relationship was probably instrumental in the ability to cultivate awareness of symptoms and the sense of confidence and reassurance, 2 of the main themes found in this qualitative analysis to navigate the post-hospitalization time.

Because participant engagement was found to be a predominant theme in this qualitative study, our results on the Working Alliance Inventory, ${ }^{37}$ a validated tool that was used to assess the therapeutic relationship, were particularly reassuring, showing that participants scored $87 \%$ of the maximum score in all 3 therapeutic subdomains of task, bond, and goal in indicating the effectiveness of the health-coaching intervention on participant engagement.

Our theme of increased health-care system access has also been reported by other groups as a major component of successful remote or telemedicine interventions ${ }^{38-40}$ and particularly important during a COPD exacerbation. The results of both the participant interviews and focus group further strengthen the importance of concretely having a point of contact during times of uncertainty.

Motivational interviewing may represent a scaffold to teach mindful communication that makes a difference. Motivational interviewing-based health-coaching interventions that were delivered over the telephone contributed to better outcomes, ${ }^{9}$ whereas non-motivational interviewing coaching resulted in little ${ }^{41}$ to no significant change in physiological or psychosocial outcomes..$^{42,43}$

In times in which health-coaching interventions have become more popular, the specific components of health coaching proposed in the triangulation analysis that may contribute to better quality of life (eg, awareness and confidence) and improved health outcomes (perception of improved health-care access) represent a step forward in our understanding of the mechanics of the health-coaching intervention. These cognitive and behavioral constructs are modifiable through intervention and are a necessary part of the coaching intervention above and beyond a positive coaching relationship..$^{44,45}$

\section{Limitations}

We cannot rule out sampling bias, in that we interviewed patients who were not deceased and who agreed to 

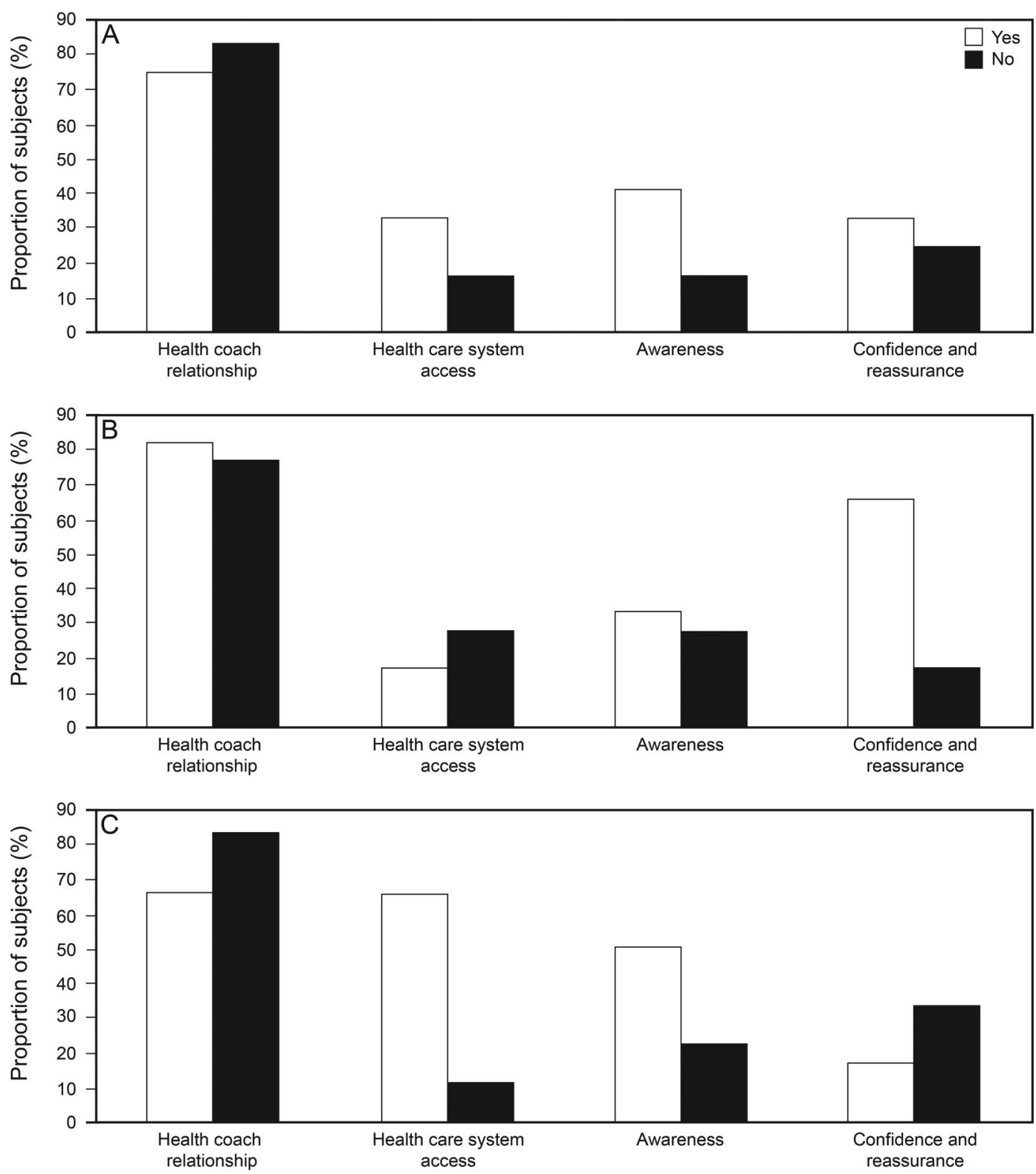

Fig. 1. A: Improvements in Chronic Respiratory Questionnaire emotional summary score (quality of life) at 6 months. Yes $=>0.5$ points, which is the minimally clinically important difference. B: Improvements in chronic respiratory questionnaire physical summary score (quality of life) at 6 months. Yes $=>0.5$ points, which is the minimally clinically important difference. C: Improvement in hospitalization at 12 months. Yes $=$ no hospitalization within 12 months; No = at least one hospitalization within 12 months.

be interviewed. To overcome the effect of social desirability, we used methods to increase the validity and reliability of our qualitative data. ${ }^{27} \mathrm{We}$ interviewed the participants and coaches at the end of the study, so memory and other factors may have affected recall.

\section{Practical Implications}

The data presented in this study inform and extend the results of the clinical trial and may help in the refinement of the tested coaching intervention. In the management of COPD, health coaches could assist patients with adherence to medications, engaging in activities (including exercise), building collaborative plans on how to respond to exacerbations of COPD, and coordinating care between the patient and his or her care team (including nurses, physiotherapists, primary care providers, respiratory therapists, and specialty providers).

\section{Conclusions}

The themes we found are seminal to start to understand the mechanistic effect of the health-coaching intervention. 


\section{Health Coaching in Severe COPD}

Our results agree with previously proposed pathways ${ }^{46}$ through which communication and a working alliance can lead to better well-being and overall outcomes. Our healthcoaching intervention addressed core concepts to forge partnerships and to create a platform for patient activation through better listening, to recognize patients as the true experts in their condition, to understand reasons for their own current behavior, and to empower them to move forward to achieve what is important to them. ${ }^{3}$ The environment created through meaningful conversation may have facilitated the behavior change ${ }^{36}$ that impacted hard outcomes like decreasing rehospitalizations in COPD and the sustainable improvement in the quality of life found in our recently published randomized study. ${ }^{26}$

\section{REFERENCES}

1. Eakin MN, Rand CS, Borrelli B, Bilderback A, Hovell M, Riekert KA. The effectiveness of motivational interviewing to reduce head start children's secondhand smoke exposure. a randomized clinical trial. Am J Respir Crit Care Med 2014;189(12):1530-1537.

2. Borrelli B, Riekert KA, Weinstein A, Rathier L. Brief motivational interviewing as a clinical strategy to promote asthma medication adherence. J Allergy Clin Immunol 2007;120(5):1023-1030.

3. Benzo RP. Mindfulness and motivational interviewing: two candidate methods for promoting self-management. Chron Respir Dis 2013;10(3):175-182.

4. Sharma AE, Willard-Grace R, Hessler D, Bodenheimer T, Thom DH. What happens after health coaching? Observational study 1 year following a randomized controlled trial. Ann Fam Med 2016;14(3): 200-207.

5. Kivelä K, Elo S, Kyngäs H, Kääriäinen M. The effects of health coaching on adult patients with chronic diseases: a systematic review. Patient Educ Couns 2014;97(2):147-157.

6. Dennis SM, Harris M, Lloyd J, Powell Davies G, Faruqi N, Zwar N. Do people with existing chronic conditions benefit from telephone coaching? A rapid review. Aust Health Rev 2013;37(3):381-388.

7. Thom DH, Hessler D, Willard-Grace R, DeVore D, Prado C, Bodenheimer T, Chen EH. Health coaching by medical assistants improves patients' chronic care experience. Am J Manag Care 2015;21(10): 685-691.

8. Walters JA, Cameron-Tucker H, Courtney-Pratt H, Nelson M, Robinson A, Scott J, et al. Supporting health behaviour change in chronic obstructive pulmonary disease with telephone health-mentoring: insights from a qualitative study. BMC Fam Pract 2012;13:55.

9. Linden A, Butterworth SW, Prochaska JO. Motivational interviewing-based health coaching as a chronic care intervention. J Eval Clin Pract 2010;16(1):166-174.

10. Wolever RQ, Dreusicke M, Fikkan J, Hawkins TV, Yeung S, Wakefield J, et al. Integrative health coaching for patients with type 2 diabetes: a randomized clinical trial. Diabetes Educ 2010;36(4):629639.

11. Thomas ML, Elliott JE, Rao SM, Fahey KF, Paul SM, Miaskowski C. A randomized, clinical trial of education or motivational-interviewing-based coaching compared to usual care to improve cancer pain management. Oncol Nurs Forum 2012;39(1):39-49.

12. Phillips CO, Wright SM, Kern DE, Singa RM, Shepperd S, Rubin HR. Comprehensive discharge planning with postdischarge support for older patients with congestive heart failure: a meta-analysis. JAMA 2004;291(11):1358-1367.
13. McAlister FA, Lawson FM, Teo KK, Armstrong PW. A systematic review of randomized trials of disease management programs in heart failure. Am J Med 2001;110(5):378-384.

14. Jack BW, Chetty VK, Anthony D, Greenwald JL, Sanchez GM, Johnson AE, et al. A reengineered hospital discharge program to decrease rehospitalization: a randomized trial. Ann Intern Med 2009; 150(3):178-187.

15. Yu DS, Thompson DR, Lee DT. Disease management programmes for older people with heart failure: crucial characteristics which improve post-discharge outcomes. Eur Heart J 2006;27(5):596-612.

16. Kasper EK, Gerstenblith G, Hefter G, Van Anden E, Brinker JA, Thiemann DR, et al. A randomized trial of the efficacy of multidisciplinary care in heart failure outpatients at high risk of hospital readmission. J Am Coll Cardiol 2002;39(3):471-480.

17. Katz PP, Julian LJ, Omachi TA, Gregorich SE, Eisner MD, Yelin $\mathrm{EH}$, Blanc PD. The impact of disability on depression among individuals with COPD. Chest 2010;137(4):838-845.

18. Katz P, Morris A, Gregorich S, Yazdany J, Eisner M, Yelin E, Blanc $P$. Valued life activity disability played a significant role in self-rated health among adults with chronic health conditions. J Clin Epidemiol 2009;62(2):158-166.

19. Coventry PA, Gemmell I, Todd CJ. Psychosocial risk factors for hospital readmission in COPD patients on early discharge services: a cohort study. BMC Pulm Med 2011;11:49.

20. Xu W, Collet JP, Shapiro S, Lin Y, Yang T, Platt RW, et al. Independent effect of depression and anxiety on chronic obstructive pulmonary disease exacerbations and hospitalizations. Am J Respir Crit Care Med 2008;178(9):913-920.

21. Ng TP, Niti M, Tan WC, Cao Z, Ong KC, Eng P. Depressive symptoms and chronic obstructive pulmonary disease: effect on mortality, hospital readmission, symptom burden, functional status, and quality of life. Arch Intern Med 2007;167(1):60-67.

22. Gudmundsson G, Gislason T, Janson C, Lindberg E, Hallin R, Ulrik $\mathrm{CS}$, et al. Risk factors for rehospitalisation in COPD: role of health status, anxiety and depression. Eur Respir J 2005;26(3):414-419.

23. Dahlén I, Janson C. Anxiety and depression are related to the outcome of emergency treatment in patients with obstructive pulmonary disease. Chest 2002;122(5):1633-1637.

24. Eisner MD, Blanc PD, Yelin EH, Katz PP, Sanchez G, Iribarren C, Omachi TA. Influence of anxiety on health outcomes in COPD. Thorax 2010;65(3):229-234.

25. Benzo R, Vickers K, Ernst D, Tucker S, McEvoy C, Lorig K. Development and feasibility of a self-management intervention for chronic obstructive pulmonary disease delivered with motivational interviewing strategies. J Cardiopulm Rehabil Prev 2013;33(2):113123.

26. Benzo R, Vickers K, Novotny PJ, Tucker S, Hoult J, Neuenfeldt P, et al. Health coaching and chronic obstructive pulmonary disease rehospitalization: a randomized study. Am J Respir Crit Care Med 2016;194(6):672-680.

27. Bellg AJ, Borrelli B, Resnick B, Hecht J, Minicucci DS, Ory M, et al. Enhancing treatment fidelity in health behavior change studies: best practices and recommendations from the NIH Behavior Change Consortium. Health Psychol 2004;23(5):443-451.

28. Neff K. Self-compassion: an alternative conceptualization of a healthy attitude toward oneself. Self Identity 2003;2:85. doi: 10.1080/ 15298860390129863.

29. Strauss A, Corbin J. Basics of qualitative research. Newbury Park, California: Sage; 1990.

30. Patton MQ. Qualitative research and evaluation methods. Thousand Oaks, California: Sage; 2002

31. Patton MQ. Enhancing the quality and credibility of qualitative analysis. Health Serv Res 1999;34(5 Pt 2):1189-1208. 


\section{Health Coaching in Severe COPD}

32. Williams JE, Singh SJ, Sewell L, Guyatt GH, Morgan MD. Development of a self-reported Chronic Respiratory Questionnaire (CRQ-SR). Thorax 2001;56(12):954-959.

33. Jones PW. Interpreting thresholds for a clinically significant change in health status in asthma and COPD. Eur Respir J 2002;19(3):398404.

34. Bucknall CE, Miller G, Lloyd SM, Cleland J, McCluskey S, Cotton $\mathrm{M}$, et al. Glasgow supported self-management trial (GSuST) for patients with moderate to severe COPD: randomised controlled trial. BMJ 2012;344:e1060.

35. Greening NJ, Williams JE, Hussain SF, Harvey-Dunstan TC, Bankart MJ, Chaplin EJ, et al. An early rehabilitation intervention to enhance recovery during hospital admission for an exacerbation of chronic respiratory disease: randomised controlled trial. BMJ 2014; 349:g4315.

36. Miller WR, Rollnick S. Ten things that motivational interviewing is not. Behav Cogn Psychother 2009;37(2):129-140.

37. Bennett JK, Fuertes JN, Keitel M, Phillips R. The role of patient attachment and working alliance on patient adherence, satisfaction, and health-related quality of life in lupus treatment. Patient Educ Couns 2011;85(1):53-59.

38. Vatnøy TK, Thygesen E, Dale B. Telemedicine to support coping resources in home-living patients diagnosed with chronic obstructive pulmonary disease: patients' experiences. J Telemed Telecare 2017; 23(1):126-132.

39. Fairbrother P, Pinnock H, Hanley J, McCloughan L, Sheikh A, Pagliari C, McKinstry B. Exploring telemonitoring and self-management by patients with chronic obstructive pulmonary disease: a qual- itative study embedded in a randomized controlled trial. Patient Educ Couns 2013;93(3):403-410.

40. Gorst SL, Coates E, Armitage CJ. "It's sort of a lifeline": chronic obstructive pulmonary disease patients' experiences of home telehealth. Health Psychol 2016;35(1):60-68.

41. Brodin N, Eurenius E, Jensen I, Nisell R, Opava CH. Coaching patients with early rheumatoid arthritis to healthy physical activity: a multicenter, randomized, controlled study. Arthritis Rheum 2008; 59(3):325-331.

42. Blackberry ID, Furler JS, Best JD, Chondros P, Vale M, Walker C, et al. Effectiveness of general practice based, practice nurse led telephone coaching on glycaemic control of type 2 diabetes: the Patient Engagement And Coaching for Health $(\mathrm{PEACH})$ pragmatic cluster randomised controlled trial. BMJ 2013;347:f5272. doi: 10.1136/bmj.f5272.

43. Patja K, Absetz P, Auvinen A, Tokola K, Kytö J, Oksman E, et al. Health coaching by telephony to support self-care in chronic diseases: clinical outcomes from the TERVA randomized controlled trial. BMC Health Serv Res 2012;12:147.

44. Clark MM, Bradley KL, Jenkins SM, Mettler EA, Larson BG, Preston HR, et al. Improvements in health behaviors, eating self-efficacy, and goal-setting skills following participation in wellness coaching. Am J Health Promot 2016;30(6):458-464.

45. Clark MM, Bradley KL, Jenkins SM, Mettler EA, Larson BG, Preston HR, et al. The effectiveness of wellness coaching for improving quality of life. Mayo Clin Proc 2014;89(11):1537-1544.

46. Street RL Jr, Makoul G, Arora NK, Epstein RM. How does communication heal? Pathways linking clinician-patient communication to health outcomes. Patient Educ Couns 2009;74(3):295-301.

This article is approved for Continuing Respiratory Care Education credit. For information and to obtain your CRCE

(free to AARC members) visit

www.rcjournal.com

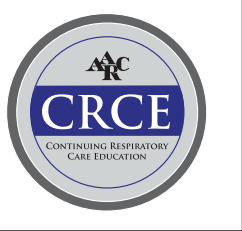

